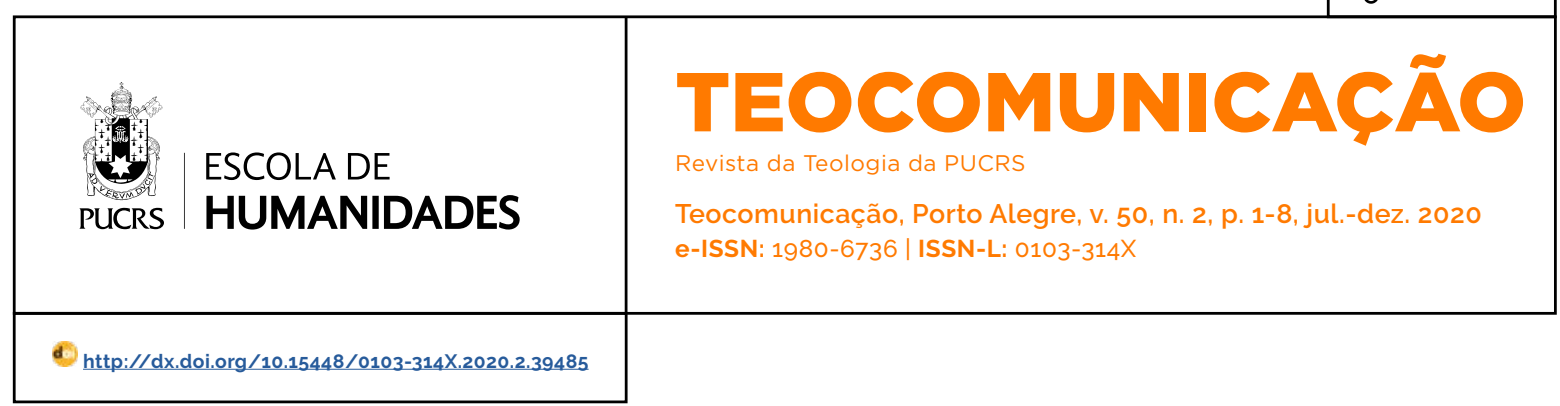

SEÇÃo

\title{
A Torá como elemento de memória e construção identitária na Yehud persa
}

The Torah as memory element and identity construction in persian Yehud

Torah como elemento de la memoria y la creación de identidad en Yehud persa

Rogério Lima de Moura ${ }^{1}$ orcid.org/0000-0001-6523-4009 rogeriocomlima@gmail.com

Recebido em: 11/12/2019. Aprovado em: 25/6/2020. Publicado em: 23/12/2020.
Resumo: Este artigo discutirá a instrumentalização da Torá por grupos de repatriados no Periodo do Segundo Templo. Na primeira parte do estudo, analisaremos a Torá como texto de memória, de tradições inventadas, e como objeto de disputa ideológica. Na segunda parte da pesquisa, faremos uma sucinta história da pesquisa e da composição da Torá, para mostrarmos a complexidade das memórias, narrativas e tradições de seus textos. E, por fim, faremos um breve comentário de um texto mítico fundante para a inserção da Torá na comunidade do pós-exilio.

Palavras-chave: Torá. Memória. Identidade. Neemias.

Abstract: This Article discusses the instrumentalization of the Torah by groups of returnees in the Second Temple Period. In the first part of the study we will analyze the Torah as a text of memory and invented traditions and as an object of ideological dispute. In the second part of the research we will make a brief history of Torah research and composition to show the complexity of the memories, narratives and traditions of his texts. Finally, we will comment briefly on a foundational mythical text for the insertion of the Torah in the post-exile community.

Keywords: Torah. Memory. Identity. Nehemiah.

Resumen: Este artículo discutirá la instrumentalizacion de la Torá por grupos de retornados en el Período del Segundo Templo. En la primera parte del estudio, analizaremos la Torá como un texto de memoria, de tradiciones inventadas y como objeto de disputa ideológica. En la segunda parte de la investigacion, haremos una breve historia de la investigacion y la composicion de la Torá, para mostrar la complejidad de los recuerdos, narraciones y tradiciones de sus textos. $Y$ finalmente, haremos un breve comentario sobre un texto fundacional mítico para la inserción de la Torá en la comunidad posterior al exilio.

Palabras clave: Torá. Memoria. Identidad. Nehemias.

\section{Introdução}

No IV século AEC os grupos que estavam voltando da Babilônia encontraram Yehud povoada por pessoas que, de uma forma ou de outra, compartilhavam cosmovisões da realidade com os exilados. Eram também adoradores da divindade YHWH. Diferentemente do que afirma Crônicas 36, 21, Jerusalém permaneceu ocupada pelos chamados povos da terra (ver II Reis 24).

Dentre esses diversos agrupamentos na Jerusalém dos inícios do Período do Segundo templo (515 AEC), havia, além das populações autóctones de judaítas que não foram enviados a Babilônia, grupos advindos da Samaria e regiões próximas. 
Para os que retornaram, entre eles sacerdotes e escribas, restavam tentar recuperar novamente o controle da cidade de Jerusalém e do templo que fora perdido com a destruição provocada pelos babilônios. Para isso, foi preciso voltar ao passado para as antigas tradições e memórias para legitimar o presente.

A memória é um elemento capacitador de formação de identidade. Essa Identidade, podemos afirmar assim, é uma relação entre o público e o privado, entre o pessoal e o exteriorizado. Internaliza-se símbolos, visões de mundo de um determinado grupo e fixa-se dentro do lugar cultural habitado (HALL, 2015, p. 11). A memória, por sua vez, é maleável, construída e de certa forma se adapta de acordo com os agentes que promovem sua reprodução na cultura. Memória e esquecimento são dois conceitos importantes para lidar com a construção de realidades.

Jan Assmann (2008, p. 116) afirma que a memória cultural é uma forma de memória coletiva compartilhada por pessoas e traz significados profundos de pertença e identidade de grupo. Ela é institucionalizada e exteriorizada em formas simbólicas que fornecem subsidios ideológicos.

Na Jerusalém destruida pelos babilônios, podemos perceber os principais simbolos de outrora como templo e a terra de Judá perdidos para estrangeiros que provocaram novas construções identitárias nos grupos políticos e religiosos entre os exilados a partir do século $V$ AEC.

Como legitimadora de instituições e de grupos minoritários que possuem certo capital político e gera influência na sociedade, a memória é disputada pelo poder e as narrativas relembradas na cultura sobre determinado acontecimento fundante pode ser retrabalhado e tornar-se mito que se solidifica nos aparelhos propagandísticos da instituição.

Paul Ricoeur (2007, p. 40) nos explica esse tipo de funcionamento e estratégia:

No plano mais profundo, o das mediações simbólicas da ação, a memória é incorporada à constituição da identidade por meio da função narrativa. A ideologização da memória torna-se possivel pelos recursos de variação oferecidos pelo trabalho de configuração narrativa. E como os personagens da narrativa são postos na trama simultaneamente à história narrada, a configuração narrativa contribui para modelar a identidade dos protagonistas da ação ao mesmo tempo que os contornos da própria ação.

Nesse sentido, a Torá desempenha função importante na construção dos discursos ideológicos daqueles que retornaram à terra de Yehud. Ela possui amplas camadas de narrativas legitimadoras para a afirmação de certos grupos que se julgam detentores de certas tradições.

Além disso, nesse caso, a Torá serve como um conjunto de tradições inventadas com a finalidade de autenticar a atuação dos repatriados que foram exilados e voltam para Jerusalém. Hobsbawn e Ranger (2017, p. 7) afirma:

O termo "tradição inventada" é utilizado num
sentido amplo, mas nunca indefinido. Inclui
tanto as tradições realmente inventadas, cons-
truidas e formalmente institucionalizadas, quan-
to as que surgiram de maneira mais dificil de
localizar num periodo limitado e determinado
de tempo - às vezes coisa de poucos anos ape-
nas - e se estabeleceram com enorme rapidez.

O exemplo clássico sobre o que o autor citado acima afirma na tradição da Torá é a ideia da composição mosaica de tais textos para fornecer autoridade a um conjunto de tradições justapostas e de diferentes origens e que foram costuradas por redatores artificialmente.

Hindy Najman (2000, p. 212-213) assim explica o uso do pseudônimo "Moisés" para dar a ideia de escrita e autoria de determinadas tradições da Torá:

\begin{abstract}
Mesmo se existiu uma coleção de escritos conhecido como a Torá de Moisés e talvez se o termo Torá de Moisés foi usado com frequência para se referir para esta coleção, isto não significa que a função primeira do termo foi o nome desta coleção de escritos. Em vez disso, poderia ser que a função primeira deste termo foi para conferir autoridade.
\end{abstract}

Portanto, a nosso ver, dois elementos são chave para interpretar o uso da Torá por grupos no início do Período do Segundo Templo em Yehud. Primeiro, a memória moldada de acordo com o momento da Jerusalém da província persa de Yehud, em que se procura no passado e em personagens coloridos miticamente pelas tradições de certas narrativas para ressignificar o presente. Segundo, a invenção de tradições cujos textos 
reunidos da Torá, apontados ficcionalmente como vindos de Moisés, fortaleceram a política de retorno e retomada de poder em Yehud. Textos esses que tiveram sua utilização como função primeva no IV século AEC para fortalecer os grupos de exilados que retornaram da Babilônia. Tais grupos se transformaram em intérpretes e interlocutores da Torá que, segundo a concepção mítica, fora entregue a Moisés pela própria divindade. Os sacerdotes e escribas se tornam, assim como Moisés, os mediadores da Torá.

Sabemos que as tradições da Torá tiveram uma trajetória longa até a formação do que temos hoje dos cincos rolos e cujo conteúdo consta com narrativas construidas sequencialmente. Mas como se formou a Torá? É o que analisaremos no nosso próximo tópico.

\section{A formação e composição de longa duração da Torá}

Em nossa introdução levantamos a hipótese de que a Torá foi utilizada no início do Periodo do Segundo Templo para legitimar os grupos vindos da Babilônia no IV século AEC.

Foi observado que a Torá é uma coleção de memórias e tradições inventadas do passado. Essas tradições cuja autoridade era reforçada com a autoria pseudônima de Moisés deu a esses grupos a chance de fortalecer seus discursos de retomada de influência religiosa e política em Jerusalém.

Agora, falaremos sucintamente sobre como o processo de composição desses escritos vieram a se reunir segundo a hipótese cientíica dos estudos da Torá. O intuito é demonstrar que a Torá se formou com diversas narrativas, tradições e memórias que eram separadas em um primeiro momento, antes do estágio avançado de formação no Periodo do Segundo Templo.

No século XIX EC Julius Wellhausen definitivamente direcionou o paradigma teórico da composição da Torá que viraria uma espécie de dogma acadêmico das leituras e estudos dos cinco primeiros livros da Biblia Hebraica.

Logicamente que Wellhausen estava alinhado com o pensamento de precursores como Baruch Spinoza que, já no século XVII EC, defendia que
Moisés não poderia ter escrito a Torá, mas sim o escriba Esdras.

Spinoza naturalmente entendia que as diversas incongruências sob a ótica literária só poderiam ser explicadas fora da hipótese da composição mosaica da Torá. Spinoza também foi o primeiro a presumir que a Torá foi produto de autoria do pós-exilio.

Outro nome que antecedeu a Wellhausen foi o do pastor protestante Henning Bernhard Witter, que, em um estudo clássico de Gn 1-3, chamou a atenção para os diferentes nomes da divindade que aparecem nesses capítulos. Mesmo assim, Witter ainda atribuía a Moisés a composição da Torá.

Por sua vez, o médico de Luís XV, Jean Astruc, baseado nas diferenças de nomes divinos nos textos da Torá - que já tinham sidos observados por Witter -, defendeu a hipótese de que Moisés se servira de três fontes distintas. Mas o paradigma da autoria mosaica com esses nomes ainda persistia.

Podemos observar que nesse estágio da discussão sobre as diferenças de nomes da divindade já há de certa maneira uma percepção que entre os blocos e pericopes da Torá existem estilos narrativos diferentes.

Foi realmente com Julius Wellhausen que as várias teorias ganham sua configuração final para defender que a Torá é uma compilação de quatro documentos: Javista, Eloísta, Deuteronômio e Escrito Sacerdotal. Essa hipótese, além de apontar as diferenças de nomes da divindade que varia entre Elohim e YHWH, tenta responder os problemas literários encontrados na Torá como as diversas repetições, narrativas, fraturas e estilos diferentes entre camadas e pericopes.

Além disso, a hipótese de Wellhausen analisou não só os textos do ponto de vista literário, mas forneceu subsídios para que ele olhasse a religião do antigo Israel evolutivamente.

Cada uma dessas fontes irá ser escrita em determinados periodos da História de Israel:

Javista - 950 AEC - Época do reinado de Salomão em Jerusalém

Eloísta - 800 AEC - No reino do Norte, Israel 
Deuteronômio - VII século AEC - Reinado de Josias

Escrito Sacerdotal - 550 AEC - Exilio na Babilônia

Segundo Römer (2010, p. 90):

A pesquisa de Wellhausen a partir de cinco instituições (o lugar do culto, os sacrificios, as festas, o clero, o dizimo) faz aparecer a cada vez o mesmo esquema de evolução: pluralidade. centralização, ritualização [...]. Essa visão evolutiva da religião de Israel confirma Wellhausen na ideia de que a Lei não está na origem nem do antigo Israel nem do Pentateuco, mas se torna o fundamento do judaísmo a partir da época pós-exilica.

Como afirmamos, a hipótese de Wellhausen se manteve firme até meados de 1970. A partir desse periodo, uma série de pesquisas colocaria em xeque a teoria exposta acima e mudaria a direção da pesquisa.

O primeiro pesquisador desse periodo que citaremos é Rolf Rendtorff que defendeu que na Torá existem divisões claras e temáticas que separam os blocos narrativos: criação, patriarcas, êxodo, permanência no deserto, Sinai etc. (SKA, 2016, p. 19).

A diferença entre a proposta de Wellhausen e a nova hipótese de Rendtorff era bem estabelecida: ao invés de fontes com grandes blocos narrativos que teriam um fio condutor claro, com estilos e ideologia de fácil reconhecimento teriamos fragmentos temáticos, unidades menores que na sua origem eram separadas.

Diferentemente do Deuteronômio e a Fonte Sacerdotal comumente chamada de Fonte $\mathrm{P}$ (Priestly) que podemos com certa facilidade identificar o estilo e a ideologia que perpassa suas narrativas é difícil dizer o mesmo dos antigos Javista e Eloista.

O Eloísta já a muito tempo tem sido descartado por um número grande de estudiosos da Torá. O Javista ainda é defendido por alguns nomes como o de John Van Seters que afirma que o Javista é um historiador que tem seu lugar vivencial no exilio.

Van Seters inverte a ordem das datações tradicionais das fontes afirmando que J é um autor pós deuteronômico que em alguns casos corrige essa tradição. Assim, o Javista teria mais abertura a concepções onde os deuteronomistas seriam mais conservadores (SETERS, 1999, p. 60-61).

Em matéria de identidade de grupo, o Javista segundo essa concepção, seria mais inclusivo, uma vez que as narrativas patriarcais mostram, por exemplo, os personagens abertos a estrangeiros e aos seus deuses, diferente dos deuteronomistas, cuja ideologia caracteriza-se por uma visão exclusivista da fé javista e pela rejeição das cosmovisões e das religiões estrangeiras.

Ponto passivo na discussão da formação da Torá é a existência da Fonte Sacerdotal. Esses blocos são fáceis de identificar principalmente pela ênfase no culto. Não foram envolvidos nas discussões que colocaram em dúvidas o Eloísta e o Javista. A discussão envolvendo a Fonte $P$ é focada em perguntas a respeito de sua natureza, extensão, conclusão, sua teologia e a relação com o Código de Santidade (LV 17-26). Além disso, os questionamentos sobre P inclui saber se o Escrito Sacerdotal poderia ser uma obra independente ou apenas uma camada redacional que comentaria e complementaria tradições antigas (SKA, 2003, p. 159).

Recentemente pesquisadores da Torá têm deixado de lado a sigla J para falar de textos que foram escritos no pré-exilio para denominar esses blocos de textos pré-sacerdotais, ou seja, tradições que teriam surgido antes da formação do Escrito Sacerdotal no período do exilio. O problema aumenta quando se afirma que textos não sacerdotais não sejam somente anteriores a $\mathrm{P}$, mas posteriores ao escrito básico sacerdotal. Essa camada é designada com a sigla pós-P, ou seja, pós-sacerdotal e seriam textos escritos inclusive no periodo helênico (NIHAN; RÖMER, 2010, p. 108-109). Podemos ver a complexidade do debate e das teorias sobre as camadas da Torá.

Dentro da perspectiva da teoria dos fragmentos e das pequenas unidades, cada bloco narrativo temático nasceu separadamente em diversas localidades do antigo Israel e de Judá. Foram juntadas no pós-exilio provavelmente pelos sacerdotes do Período do Segundo Templo. Essas pequenas unidades foram crescendo ao longo do processo histórico de longa duração da 
composição dos grandes temas da Torá, como criação, patriarcas, êxodo etc.

Em um primeiro estágio teriamos um Tetrateuco com Gn-Nm e, posteriormente, o Deuteronômio seria juntado a esses textos e a Torá se tornaria, então, um Pentateuco. Isso se deve principalmente à ideia de que o Deuteronômio serviria de introdução à chamada História Deuteromonista. Mas as hipóteses variam e são diversificadas. Alguns pesquisadores ainda defendem um Hexateuco na linha de Gerhard Von Rad por achar que a promessa da terra dentro de um esquema temático se concretiza somente em Josué.

A teoria dos fragmentos é, inclusive, compativel com as descobertas arqueológicas das últimas décadas. A hipótese wellhausiana de escrita nos periodos do reinado de Salomão a partir do século XAEC só poderia ser aceita se houvesse realmente uma grande estrutura para dar condições de escrita naquele período. Ao invés disso, o que se comprova hoje é a ausência de provas de produção literária no periodo salomônico. Diferentemente de uma grande monarquia, Jerusalém no $X$ século AEC seria apenas uma pequena vila ainda em desenvolvimento (FINKELSTEIN, 2018, p. 157-203).

A escrita provavelmente surgiu com maior força em Israel Norte com a monarquia mais especificamente de Jeroboão II. Nesse período, a arqueologia oferece dados mais claros. Tradições como as narrativas de Jacó, por exemplo, poderiam ter se iniciado nos santuários de Penuel e Betel ligadas àquela região.

Posteriormente, relatos que se originaram em Israel Norte podem ter sidos juntados com as tradições oriundas de Judá a partir do VII século AEC com a queda de Israel no VIII AEC. Esse acontecimento se deu por causa da invasão assíria e a consequente recepção de rolos advindos daquela região por sacerdotes de Judá ligados ao templo de Jerusalém. Teriamos nesse periodo do VII século AEC a primeira compilação de escritos que posteriormente chamariamos de Torá. Narrativas fundantes do reino do norte como o êxodo seriam juntadas às narrativas dos patriarcas somente tardiamente pelo redator sacerdotal no Periodo do Segundo Templo (SCHMID, 2013, p. 110-111).
Assim, em um primeiro momento, teríamos duas narrativas míticas fundantes separadas, uma com enfoque no elemento genealógico, ou seja, são israelitas àqueles que são descendentes de Abraão, Isaque e Jacó e outra com o fundamento de que Israel nasceu no Egito e fora libertado por YHWH no êxodo.

Podemos, então, finalizar esse tópico afirmando o seguinte: A Torá foi formada por diversas tradições surgidas nos reinos de Israel e de Judá a partir do VIII século AEC. A princípio, suas narrativas eram separadas em pequenos blocos com temas específicos. Posteriormente, em um processo de longa duração, a partir do VII século $A E C$ e que perpassa os séculos subsequentes, começa-se a se juntar tradições dispares para a formação de uma história das origens homogênea. As histórias patriarcais servem de preâmbulo para a história do êxodo.

A Torá a partir de então, possivelmente no periodo do pós-exilio, já contém juntas as formas sequenciais patriarcas-êxodo aglutinando essas duas tradições e memórias que permaneceram do antigo Israel Norte e de Judá. No IV século AEC seu texto provavelmente ganha importância e proeminência. Qual foi o momento da ascensão da Torá na comunidade de Yehud? É o que veremos no nosso próximo tópico onde analisaremos a narrativa fundante da Torá como texto comunitário de $\mathrm{Ne} 8$.

\section{Neemias 8 como texto mítico fundante da inserção da Torá na Comunidade do Segundo Templo}

Neemias 8 é de suma importância para o que estamos discutindo nesse artigo. Afinal de contas, começamos em nossa introdução afirmando que a Torá é uma compilação de diversas memórias e tradições que se originaram em tempos antigos.

Essas tradições e memórias foram moldadas de acordo com a situação existencial e cultural da comunidade de exilados que voltaram da Babilônia para Jerusalém. A destruição da cidade pelos babilônios é uma ruptura que marca a importância que as tradições de Israel e Judá tomaram a partir de então. 
Podemos levar agora a discussão adiante posicionando a questão da seguinte maneira: o recorte histórico da Torá que formamos através das discussões sobre suas tradições e narrativas nos levam a datar os séculos VII AEC ao IV AEC como o período da sua composição. No IV século AEC, os textos dos cinco primeiros rolos da Biblia Hebraica já estão estruturados na sequência que conhecemos hoje na sua maior parte. Um indício é a formação da Septuaginta que segue a ordem dos textos da Torá. A tradução da Torá para a língua grega já estava em circulação no século III AEC no período tardio sadoquita (III/II $A E C)$ e no periodo hasmoneu (II/I AEC).

Além disso, como verificamos no tópico anterior, as diversas tradições da Torá como o Deuteronômio e o Escrito Sacerdotal foram compilados e juntados em uma única narrativa no período que abarca provavelmente o século IV AEC.

Neemias 8 é uma narrativa que serve para nos auxiliar na hipótese de sua composição no período persa. É um mito fundador e legitimador do início do uso dos escritos da Torá pela comunidade do Segundo Templo a partir do final do recorte temporal que propomos.

Para analisar como o narrador de Neemias insere o tema da Torá no capítulo 8 passaremos agora à estrutura do capítulo. Dessa maneira, dividimos a perícope da seguinte forma:
a) A golá reunida (1-2);
b) Leitura da Torá (3-7);
c) Leitura e explicação da Torá (8-9);
d) Comemorações Litúrgicas da golá (10-12).

Dividimos a narrativa em quatro recortes $A$ partir da estrutura acima iremos ao comentário da pericope para vermos a função mítica da inserção da Torá na comunidade que Neemias descreve.

\subsection{A Golá Reunida (1-2)}

Nesses dois versículos a comunidade dos repatriados está reunida aguardando a leitura do rolo da Torá de Moisés pelo escriba Esdras. A expressão "todo o povo" que aparece são provavelmente os judaitas em Jerusalém que regres- saram da Babilônia, a golá.

A partir de agora, esta comunidade é chamada de Israel (cf. v. 1). A Torá é lida para aqueles que assumiram sua identidade de pertença às antigas tradições vindas do passado. Israel agora não é mais o reino do norte, mas os repatriados de Yehud que se reúnem para ler e aceitar a Torá de Moisés.

\subsection{Leitura da Torá (3-7)}

O rolo da Torá é lido à comunidade, para todos os homens que tinham "discernimento". Discernir pressupõe ouvir o que está sendo lido e compreender. Quem são os de discernimento? A assembleia reunida que ouve e compreende. A narrativa é totalmente positiva à cena mítica do que está sendo descrito.

Esdras, o escriba da Torá se coloca em pé sobre uma plataforma de madeira para que todo o povo o veja. Agora é a Torá que deve ser vista e ouvida. A narrativa é fundante não só para a Torá e sua inserção na comunidade do pós-exilio. Ela funda os alicerces dos judaísmos posteriores.

O rolo da Torá se torna objeto de devoção. Ela precisa ser vista. O título "escriba" que adjetiva Esdras demonstra prestígio. No mundo antigo, os escribas eram responsáveis por redigir cartas e manter registros administrativos. Escribas que trabalhavam no templo poderiam preservar tradições escritas e textos religiosos de caráter mítico (SCHNIEDEWIND, 2011, p. 60).

\subsection{Leitura e Explicação da Torá (8-9)}

Nessa parte da pericope, temos a leitura pública da Torá e a explicação do texto para todo o povo. Na narrativa, Esdras não possui função somente de escriba: ele é chamado também de "o sacerdote". Esse título, com o artigo definido, incorpora um elemento de identidade política e religiosa, pois possui as duas funções de suma importância na comunidade dos repatriados. São sacerdotes e escribas que legitimarão seus pressupostos ideológicos de acordo com a interpretação da Torá. No âmbito político, pode abrir portas com o governador estrangeiro e servir como porta-voz e mediador da comunidade de Jerusalém (KESSLER, 2009, p. 194-195). 
2.4 Comemorações e Assistência aos Pobres (10-12)

Por fim, a última parte da estrutura da pericope mostra a cena em que a cerimônia da leitura da Torá e da liturgia é seguida de ações de graças e bastante comida. Toda a comunidade é convidada a voltar para as suas casas e se alegrarem, além de promover a distribuição dos alimentos para aqueles que não tinham nada.

\section{$2.5 \mathrm{Ne} 8 \mathrm{como}$ propaganda dos repatriados}

O pequeno comentário que fizemos de $\mathrm{Ne} 8$ serve novamente para enfatizarmos o conteúdo mítico e fundacional que tem como objetivo reforçar a ideia de que a comunidade de Yehud dos repatriados é o verdadeiro povo de YHWH.

Esse bloco analisado não deve ser lido como um fato histórico, mas sim como uma idealização daqueles que construiram o enredo do capitulo 8. A pericope serve como uma espécie de propaganda de grupos exilados e que voltaram para Jerusalém.

Ska (2016, p. 193-194) assim afirma sobre a natureza de $\mathrm{Ne} 8$ :

A lei foi introduzida e imposta progressivamente pelo grupo que havia retornado do exilio, ou seja, pela golá. O povo da terra ou a ignorava ou não a observava. Podem-se também adivinhar sem dificuldades as objeções feitas pelo povo da terra aos que impõem a observância da Torá deles. Para o povo da terra, as regras são novas e são importadas. Não são antigas e não são nativas. A Torá, para o povo da terra, foi escrita por membros da golá na Babilônia, os quais a trouxeram consigo quando retornaram à pátria.

Esse trecho citado acima nos mostra como a invenção da tradição da Torá de Moisés foi utilizada para fins de conquista de poder políticos e religiosos que tinham como finalidade também o controle do templo.

Esses grupos formados de sacerdotes e escribas chamarão para si a autoridade única de interpretar e aplicar a Torá de Moisés à toda a comunidade de Yehud. As memórias e as tradições do passado serão lidas e relidas sob as lentes daqueles que controlarão o templo de Jerusalém a partir do século IV.
Novas identidades a partir de então serão criadas, mas na perspectiva daquilo que a Torá ensina de acordo com os sacerdotes e escribas ligados ao templo. A Torá se tornará a fronteira entre aqueles que pertencem à comunidade e aqueles que estão fora. Cria-se um "nós e eles" o que acarretará problemas e formação de novos grupos que também vão buscar legitimações na Torá, como, por exemplo, os grupos de Samaria que terão os seus cinco rolos. Assim, a Torá é potencialmente um texto cuja disputa pelas suas memórias e tradições percorre não só o Período do Segundo Templo como a história dos judaísmos.

\section{Considerações finais}

Nosso artigo analisou os aspectos composicionais da Torá e o uso que foi feito de suas memórias e tradições escritas pela comunidade dos repatriados do Periodo do Segundo Templo. Destacamos aspectos metodológicos e adentramos sucintamente no debate a respeito da origem dos seus textos.

Verificamos como a Torá se formou em um processo de longa duração entre os séculos VII a IV AEC. Esta panorâmica nos ajudou a entender como as tradições que surgiram separadas em Israel Norte e em Judá acabaram sendo juntadas por escribas para formar uma narrativa contínua dos mitos fundantes de Israel.

Analisamos $\mathrm{Ne} 8$ e abordamos os elementos miticos fundantes da inserção da Torá nessa pericope para reforçarmos nossa hipótese que os cinco livros da Biblia Hebraica a partir do século IV AEC já tinham a sua formação bem estabelecida a ponto de a Septuaginta usar seus textos como modelo.

Assim, defendemos nesse artigo que Yehud no Periodo do Segundo Templo está composta principalmente de lideranças ligadas ao templo, como escribas e sacerdotes, que se legitimam no poder político e religioso utilizando os textos da Torá.

Portanto, na nova comunidade de Jerusalém, a Torá foi usada para construção de novas identidades, mas ao mesmo tempo foi catalizadora de fronteiras e de separações entre grupos no pós-exilio. 


\section{Referências}

ASSMANN, Jan. Comunicative and Cultural Memory. In: ERLL, Astrid; NUNNING, Ansgar (ed.). Cultural Memory Studies: An International And Interdisciplinary Handbook. Berlin/New York: De Gruyter, 2008. p.109-118.

HALL, Stuart. A ldentidade Cultural na Pós-Modernidade. Rio de Janeiro: Lamparina, 2015.

HOBSBAWM, Eric; RANGER, Terence (org.). A Invenção das Tradições. Rio de Janeiro/São Paulo: Paz \& Terra, 2017.

KESSLER, Rainer. História Social do Antigo Israel. São Paulo: Paulinas, 2009.

NAJMAN, Hindy. Torah Of Moses: Pseudonymous Attributtion in Second Temple Writings. In: EVANS, Craig A. The Interpretation os Scripture in Early Judaism and Christianity: Studies in Language and Tradition. Sheffield: Sheffield Academic Press, 2000. p. 73-86.

NIHAN, Christophe; RÖMER, Thomas. O Debate Atual Sobre a Formação do Pentateuco. In: ROMER, Thomas; MACCHI, Jean-Daniel; NIHAN, Christophe (org.). Antigo Testamento: História, Escritura e Teologia. São Paulo: Loyola, 2010. p. 108-147.

RÖMER, Thomas. A Formação do Pentateuco: História da Pesquisa. In: ROMER, Thomas; MACCHI, Jean-Daniel; NIHAN, Christophe (org.). Antigo Testamento: História, Escritura e Teologia. São Paulo: Loyola, 2010. p. 85-107.

RICOEUR, Paul. A Memória, a História e o Esquecimento. Campinas: Editora da Unicamp, 2007.

SCHMID, Konrad. História e Literatura do Antigo Testamento: Uma Introdução. São Paulo: Loyola, 2013.

SCHNIEDEWIND, William M. Como A Biblia Se Tornou Um Livro. São Paulo: Loyola, 2011.

SETERS, John Van. The Pentateuch: A Social- Science Commentary. Sheffield: Sheffield Academic Press, 1999.

SKA, Jean Louis. Introdução à Leitura do Pentateuco: Chaves Para a Interpretação dos Cinco Livros da Biblia. São Paulo: Loyola, 2003.

SKA, Jean Louis. O Canteiro do Pentateuco: Problemas de Composição e de Interpretação, Aspectos Literários e Teológicos. São Paulo: Paulinas 2016.

\section{Rogério Lima de Moura}

Doutorando em Ciências da Religião pela Universidade Metodista de São Paulo (UMESP), em São Bernardo do Campo, SP, Brasil. Membro do grupo de pesquisa Arqueologia do Antigo Oriente (UMESP) e docente no curso de bacharelado em Teologia da Universidade Metropolitana de Santos (UNIMES), em Santos, SP, Brasil. Bolsista Capes.

\section{Endereço para correspondência}

Rogério Lima de Moura

Universidade Metropolitana de Santos

Rua Conselheiro Nébias, 525

Encruzilhada, 11045002

Santos, SP, Brasil 